\title{
Fatal Delayed Hemolytic Transfusion Reaction and Hyperhemolysis without Detectable Alloantibodies or Autoantibodies in a Patient with Sickle Cell Disease: A Case Report and Literature Review
}

Basile Nsimba ${ }^{1,2^{*}}$, Anoosha Habibi ${ }^{3,4}$, France Pirenne ${ }^{5}$, Pablo Bartolucci ${ }^{3,4}$, Daniel Tonduangu ${ }^{6}$, Christophe Duvoux ${ }^{7}$, Nicolas De Prost ${ }^{8}$, Maud Marcandetti ${ }^{1,2}$, Armand Mekontso-Dessap ${ }^{8}$, Frédéric Galactéros ${ }^{3,4}$ and Pascal Morel ${ }^{1}$

${ }^{1}$ Blood Bank and Immunohematology Laboratory and Haemovigilance, French Blood Establishment (EFS), France

${ }^{2}$ French Hemovigilance Network, France

${ }^{3}$ University Hospitals Henri-Mondor, Red Blood Cell Genetic Diseases Unit, France

${ }^{4}$ Mondor Institute for Biomedical Research, National Institute of Health and Medical Research, DHU A-TVB, Créteil, France

${ }^{5}$ French Establishment of the Blood, Île de France, Créteil, France

${ }^{6}$ Service of Medical Reanimation, Hôpital de Sens, F-89100 Sens, France

${ }^{7}$ Department of Hepatology, APHP, University Hospitals Henri-Mondor, Créteil, France

${ }^{8}$ Medical Resuscitation Service, APHP, University Hospitals Henri-Mondor, Créteil, France

"Corresponding author: Basile Nsimba, Chief Medical Officer, Blood bank and Immunohematology Laboratory and Haemovigilance, French Blood Establishment (EFS) Bourgogne-Franche Comté, Site de Sens, 1 avenue Pierre de Coubertin, 89100 Sens, France, Tel: +33668691133, E-mail: nsimba.basile@gmail.com

Received date: Jul 16, 2017; Accepted date: Aug 17, 2017; Published date: Aug 24, 2017

Copyright: (C) 2017 Nsimba B, et al. This is an open-access article distributed under the terms of the Creative Commons Attribution License, which permits unrestricted use, distribution, and reproduction in any medium, provided the original author and source are credited.

\begin{abstract}
Background: Sickle cell disease (SCD) is one of the most commonly inherited diseases worldwide and one of the most frequently occurring genetic disorders in France. Delayed hemolytic transfusion reaction (DHTR) is a classic complication in patients with SCD who undergo blood transfusions, and this condition may lead to hyperhemolysis syndrome (HS). DHTR is described as a transfusion complication and is often associated with antiRBC antibodies.

Case report: We report the death of a 47-year-old man of Martinican origin, with sickle cell disease (SCD) and no history of alloimmunization, who was admitted to the Sens Medical Center in July 2015 due to a vaso-occlusive crisis (VOC). An antibody screening test based on the gel technique was conducted and no anti-RBC antibodies were detected. The patient was readmitted with a VOC two days after discharge and subsequently developed DHTR/HS after transfusion episodes. He succumbed to acute complications involving severe multiple organ failure after being transferred to Henri-Mondor University Hospital in Creteil. This case report was made available thanks to our Haemovigilance Network.
\end{abstract}

Conclusion: This case demonstrates the importance of DHTR prevention using national guidelines to carefully assess indications for RBC transfusion in patients with SCD. Early diagnosis is crucial to prevent this life-threatening complication. Special attention should be given to less well-known and less-well monitored patients who may be at high risk for DHTR. In any event, DHTR/HS without detectable anti-RBC antibodies presents a clinical and biological challenge to our understanding of this disorder.

Keywords: Delayed hemolytic reaction; Sickle cell; Red blood cells; Alloantibody; Transfusion; Hyperhemolysis

\section{Introduction}

Sickle cell disease is one of the most commonly inherited diseases worldwide and one of the most frequently occurring genetic disorders in France [1]. Blood transfusion plays an important role in the management of sickle cell disease (SCD). Nevertheless, transfusion is potentially hazardous in patients with SCD and some complications, including delayed hemolytic transfusion reaction (DHTR), are not easily prevented. DHTR typically occurs in patients 5-15 days after transfusion and is often associated with a vaso-occlusive crisis characterized by the following symptoms: anemia, dark (cola-colored) urine, elevated indirect bilirubin, and increased levels of lactate dehydrogenase (LDH) $[2,3]$. It remains unknown why some cases of
DHTR directly involve or lead to hyperhemolysis syndrome (HS), causing the destruction of both donor and recipient red blood cells, brisk intravascular hemolysis, and very low levels of total hemoglobin (Hb) (below pretransfusion levels) [4-6]. HS typically causes a fall in absolute reticulocyte count (a decrease from the baseline concentration) during hemolysis, and a rise in $\mathrm{Hb}$ and reticulocyte counts often accompanies recovery [2,5]. Delayed reactions typically result from a secondary immune response in a previously transfused or pregnant patient who has developed an alloantibody, and such reactions can be life-threatening $[7,8]$. The risk of developing DHTR is the most serious consequence of alloimmunization in SCD patients. Screening tests can be used to detect these antibodies so that red blood cells free of the antigen in question may be administered. In some cases, however, the alloantibody titer may be below detectable levels at the time of pre-transfusion testing, and thus the antibody remains undiscovered [9]. The incidence of alloimmunization to red blood cell 
Citation: Nsimba B, Habibi A, Pirenne F, Bartolucci P, Tonduangu D, et al. (2017) Fatal Delayed Hemolytic Transfusion Reaction and Hyperhemolysis without Detectable Alloantibodies or Autoantibodies in a Patient with Sickle Cell Disease: A Case Report and Literature Review. J Blood Disord Transfus 8: 388. doi:10.4172/2155-9864.1000388

Page 2 of 5

antigens in transfused patients with SCD is approximately $5-36 \%$, which is greater than that in the non-sickle cell population [9]. Alloimmunization is also a risk factor for the production of red blood cell antibodies. Autoantibodies may exacerbate the hemolytic reaction, contributing to bystander hemolysis and, in some cases, explaining the destruction of both the donor's and patient's RBCs $[10,11]$. Autoantibody production occurs in approximately 6 to $10 \%$ patients who have sickle cell disease and undergo transfusion [11].

In this case report, we describe the occurrence of a fatal delayed hemolytic transfusion reaction/hyperhemolysis syndrome in a patient with SCD presenting a VOC, and we propose a management strategy for preventing and treating this transfusion complication using data from the associated literature.

\section{Case Report}

A 47-year-old male with SCD and no history of G6PD deficiency or alloimmunization was admitted to the Sens Medical Center in July 2015. The patient had been symptomatic since childhood and experienced frequent VOC episodes (2-4 episodes/year). He presented with particularly painful episodes, acute chest syndrome (ACS), and priapism. His basal $\mathrm{Hb}$ concentration was between 6.9 and $8 \mathrm{~g} / \mathrm{dL}$ and was generally treated with hydroxyurea and folic acid.

The patient's blood type was $\mathrm{O}$, phenotype $\mathrm{D}+\mathrm{C}-, \mathrm{E}-, \mathrm{c}+, \mathrm{e}+, \mathrm{K}-, \mathrm{Jka}$ +, Jkb-, Fya-, Fyb+, S-, s+, and his medical history included multiple previous transfusion episodes. These prior transfusions were not conducted at Sens Medical Center, and there was no evidence of any previous transfusion reactions. The patient was admitted to the Sens Medical Center due to a VOC which included back pain, fever ( $\mathrm{T}$ ${ }^{\circ} 38.7^{\circ} \mathrm{C}$ ), abdominal pain, a cough with purulent sputum, and brown urine. A complete blood count was ordered and did not show signs of severe anemia, taking his baseline $\mathrm{Hb}$ into account (the patient's $\mathrm{Hb}$ was $7.1 \mathrm{~g} / \mathrm{dl}$ ). He was treated for dehydration and given pain medication, antibiotics, and oxygen. No atypical red blood cell alloantibodies were detected using the indirect antiglobulin technique (antibody screening using the Bio-rad gel card). And After testing, two $\mathrm{ABO}$-compatible $\mathrm{RBC}$ units, $\mathrm{Rh}$ and Kell phenotype matched and cross-matched on day 2 were given by transfusion in accordance with national guidelines. The patient was discharged from the hospital on day 7, with an $\mathrm{Hb}$ concentration of $9.6 \mathrm{~g} / \mathrm{dl}$. Two days after the patient's discharge, he was readmitted to the same facility for another painful VOC. He was jaundiced and exhibited hemoglobinuria. At this time, his $\mathrm{Hb}$ level was $9.5 \mathrm{~g} / \mathrm{dl}$. On day 11, this level decreased to $8.9 \mathrm{~g} / \mathrm{dl}$, and one RBC unit was administered. Soon after this last transfusion, he abruptly developed severe whole body pain (day 12), and his $\mathrm{Hb}$ level dropped to $4.4 \mathrm{~g} / \mathrm{dl}$ while his plasma lactate concentration rose to 21.5 $\mathrm{mmol} / \mathrm{l}$. The patient's laboratory results and $\mathrm{Hb}$ levels during his admission/readmission to Sens Medical Center are summarized in Table 1 and Figure 1 respectively. Additional serologic testing, including direct (DAT) and indirect (IAT) tests using Bio-Rad gel cards and the gel technique (Wadiana, Grifols S.A) was negative. The patient was again treated for dehydration and given oxygen as well as large doses of morphine to control his pain; he was anxious, irritable, and drowsy.

\begin{tabular}{|c|c|c|c|c|c|c|}
\hline \multirow{2}{*}{ Parameters } & Day 1 & Day 3 & Day 7 & Day 10 & Day 11 & Day 12 \\
\hline & $\begin{array}{l}\text { First admission: } \\
\text { initial values }\end{array}$ & $\begin{array}{l}\text { After receiving } 2 \\
\text { RBC units }\end{array}$ & $\begin{array}{l}\text { Discharge } \\
\text { values }\end{array}$ & $\begin{array}{l}\text { Readmission: initial } \\
\text { values }\end{array}$ & $\begin{array}{l}\text { After receiving } 2 \\
\text { RBC units }\end{array}$ & $\begin{array}{l}\text { DHTR event after } \\
\text { receiving } 1 \text { RBC unit }\end{array}$ \\
\hline $\mathrm{Hb}(\mathrm{g} / \mathrm{dl})$ & 7.1 & 9.2 & 9.3 & 9.5 & 8.9 & 4.4 \\
\hline Hct (\%) & 22 & 28 & 27 & 28 & 27 & 13 \\
\hline Reticulocytes (Giga/l) & $\mathrm{NM}^{*}$ & NM & NM & NM & NM & NM \\
\hline WBC count (Giga/l) & 14.1 & 13.4 & 8.7 & 14.1 & 19.4 & 16.1 \\
\hline PLTs (Giga/l) & 255 & 455 & 516 & 494 & 230 & 63 \\
\hline Total bilirubin $(\mu \mathrm{mol} / \mathrm{l}))$ & NM & NM & NM & 126.2 & NM & NM \\
\hline Direct bilirubin $(\mu \mathrm{mol} / \mathrm{l}))$ & NM & NM & NM & 117.3 & NM & NM \\
\hline LDH (IU/) & NM & NM & NM & 834 & NM & NM \\
\hline AST (IU/I) & 73 & NM & NM & 89 & NM & NM \\
\hline ALT (IU/I) & 27 & NM & NM & 54 & NM & NM \\
\hline Serum creatinine $(\mu \mathrm{mol} / \mathrm{l})$ & 60 & 54 & 63 & 58 & 51 & 320 \\
\hline $\mathrm{BUN}(\mu \mathrm{mol} / \mathrm{l})$ & 1.9 & 2.3 & 0 & 3.2 & 3.1 & 12.7 \\
\hline $\operatorname{CRP}(\mathrm{mg} / \mathrm{l})$ & 25 & 47.4 & 9 & 12.7 & 49.3 & 166.3 \\
\hline INR & 1.2 & NM & NM & 1.1 & NM & 9 \\
\hline Fibrinogen (g/l) & NM & NM & NM & NM & NM & 1.25 \\
\hline
\end{tabular}


Citation: Nsimba B, Habibi A, Pirenne F, Bartolucci P, Tonduangu D, et al. (2017) Fatal Delayed Hemolytic Transfusion Reaction and Hyperhemolysis without Detectable Alloantibodies or Autoantibodies in a Patient with Sickle Cell Disease: A Case Report and Literature Review. J Blood Disord Transfus 8: 388. doi:10.4172/2155-9864.1000388

Page 3 of 5

${ }^{*} \mathrm{NM}$ : not measured

Table 1: DHTR laboratory results by day: Sens Medical Center, Sens, France.

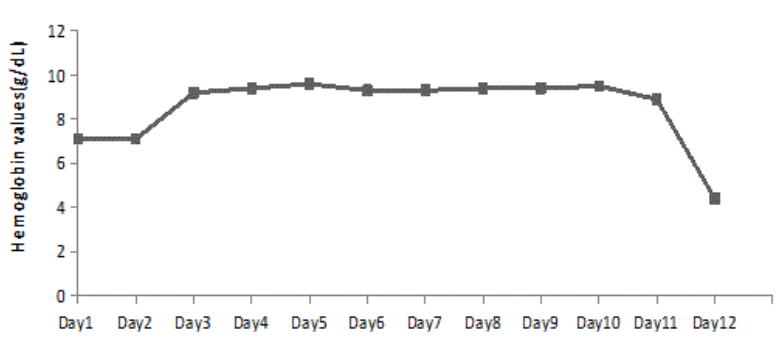

Figure 1: Delayed hemolytic transfusion reaction (DHTR) in a patient with sickle cell disease admitted into Sens Medical Center, France: Day 1: Sadmission; Day 2: Transfusion of two RBC units; Day 7: Discharge; Day 10: Readmission; Day 12: DHTR event with abrupt drop in Hb levels-transfusion of one RBC unit at 1:45 AM; two RBC units and three FFP (fresh frozen plasma) units at 1:00 PM.
On day 12, the patient received two RBC units in the intensive care unit before his same-day transfer to the Henri-Mondor University Hospital (located in Créteil, France) where he was to receive tertiary care. Upon admission, he had an $\mathrm{Hb}$ of $5.9 \mathrm{~g} / \mathrm{dl}$ and elevated blood lactate concentrations ( $>15 \mathrm{mmol} / \mathrm{l})$.

This resulted in multiple organ failure. The results of all biological testing, from admission into the Henri-Mondor University Hospital until the patient's time of death, are shown in Table 2.

Arterial blood gas measurements revealed a $\mathrm{pH}$ of 7.27, a $\mathrm{PaCO} 2$ of $38 \mathrm{mmhg}$, and $\mathrm{PaO} 2$ of $175 \mathrm{mmhg}$ at a $100 \%$ inspired oxygen fraction. His vital signs revealed a temperature of $37.1^{\circ} \mathrm{C}$, a heart rate of 118 beats per minute, a respiratory rate of 34 breaths per minute, and a blood pressure of 90/50 mmhg.

The physical exam revealed conjunctival icterus, tachycardia, and a voluminous spleen; hepatomegaly was not found. The patient received invasive monitoring and was treated with noradrenaline and aggressive fluid resuscitation to reverse hemodynamic shock; antibiotherapy with Tazocilline" (piperacillin/tazobactam) was continued.

\begin{tabular}{|c|c|c|c|}
\hline Measurements & $\begin{array}{l}\text { Day } 1 \\
\text { Admission Values } \\
\text { (transfusion: } 6 \mathrm{FFP}^{* *} \text { units) }\end{array}$ & $\begin{array}{l}\text { Day } 2 \text { Values } \\
\text { (massive transfusion of } 13 \text { RBC units, } 12 \text { FFP } \\
\text { units, and } 2 \text { platelet units) }\end{array}$ & $\begin{array}{l}\text { Day } 3 \text { Values } \\
\text { (Patient died after receiving } 1 \text { RBC unit } \\
\text { and } 3 \text { FFP units). }\end{array}$ \\
\hline $\mathrm{Hb}(\mathrm{g} / \mathrm{dl})$ & 5.9 & 6.6 & 9.5 \\
\hline Hct (\%) & 16 & 20 & 27 \\
\hline Reticulocytes (Giga/l) & 44 & NM & NM \\
\hline WBC count (Giga/l) & 11.6 & NM & NM \\
\hline PLTs (Giga/l) & 21 & 69 & 79 \\
\hline Total bilirubin $(\mu \mathrm{mol} / /)$ & $\mathrm{NM}^{*}$ & 110 & 124 \\
\hline Direct bilirubin $(\mu \mathrm{mol} / \mathrm{l})$ & NM & 83 & 111 \\
\hline LDH (IU/I) & NM & 12,500 & 6,768 \\
\hline AST (IU/I) & NM & 11,697 & 4,218 \\
\hline ALT (IU/I) & NM & 3,273 & 1,133 \\
\hline Serum creatinine $(\mu \mathrm{mol} / \mathrm{l})$ & 407 & 225 & 178 \\
\hline $\mathrm{BUN}(\mu \mathrm{mol} / \mathrm{l})$ & 13.6 & 5.8 & 3 \\
\hline INR & 7.32 & 2.68 & 4.13 \\
\hline Fibrinogen (g/l) & 0.8 & 1.4 & 2.1 \\
\hline FV (\%) & 6 & 31 & NM \\
\hline
\end{tabular}

Table 2: Laboratory results at the Henri-Mondor University Hospital, in Créteil, France. 
Citation: Nsimba B, Habibi A, Pirenne F, Bartolucci P, Tonduangu D, et al. (2017) Fatal Delayed Hemolytic Transfusion Reaction and Hyperhemolysis without Detectable Alloantibodies or Autoantibodies in a Patient with Sickle Cell Disease: A Case Report and Literature Review. J Blood Disord Transfus 8: 388. doi:10.4172/2155-9864.1000388

Page 4 of 5

It was only at this time that DHTR was diagnosed, and the decision was made to discontinue further transfusions. Given the patient's worsening hepatic function, he was scheduled for an emergency liver transplant. On day 13, he therefore underwent Molecular Adsorbent Recirculating System (MARS) [12] therapy, a form of artificial extracorporeal liver support that can be used to treat fulminant or chronic hepatic failure in patients who are waiting for a compatible donor. The patient's anemia continued to worsen, and he received a transfusion of several RBC and plasma units to maintain adequate circulation and hemostasis. Eculizumab (600 mg) was also administered on a compassionate use basis. Despite treatment, his clinical symptoms continued to worsen, and his liver transplant was cancelled. His death on day 14 was clearly transfusion-related, and this fatal adverse effect was reported to the French Haemovigilance Network.

\section{Discussion}

Here, we present a case involving a 47-year-old Martinican man with SCD who experienced a severe DHTR with no detectable pre- or post- transfusion anti-RBC antibodies. DHTR symptoms occurred on day 12 and were accompanied by hyperhemolysis. The patient had a history of multiple transfusions, but no known adverse reactions were ever reported. The fatal DHTR described here is a grade 4 adverse event attributable to transfusion and reported to our Haemovigilance Network. DHTR in sickle cell patients is a well-known complication of transfusion, entailing a significant drop in $\mathrm{Hb}(>25 \%) 5$ to 15 days after transfusion. It is often caused by a secondary immune response to an antigen on the donor's erythrocytes and leads to the destruction of transfused erythrocytes $[3,9,13]$. This complication has a reported incidence of $3 \%$ to $7 \%$ in transfused SCD patients, and $4 \%$ to $12 \%$ of DHTRs may be fatal [14]. Other DHTR cases with no detectable anti$\mathrm{RBC}$ antibodies were reported in the literature in approximately $30 \%$ of cases, but the pathophysiological mechanism mediating red cell destruction is still unclear $[3,15]$. Because cross-match and antibody screening involve inherent complications, specific antibodies cannot be systematically excluded in similar cases involving non-detectable antibodies. A negative antibody screen does not guarantee that the recipient's serum lacks clinically significant red cell antibodies. A negative antibody screen simply means that the recipient's serum does not contain antibodies that react with the method's screening cells. To illustrate this point, we provide the following example: a recipient may possess an antibody directed against a low-incidence antigen that is not present in the commercial screening cells. Furthermore, a compatible cross match does not guarantee the optimal survival of red blood cells. An antibody may not react due to the weak expression of an antigen on donor cells in a cross match, leading to a complex situation. A DHTR could occur if a preexisting, undetectable recipient antibody is activated and strengthened by a corresponding donor antigen, leading to the rapid destruction of donor cells.

Two prominent medical problems affected patient management in this case: first, the decision to administer early transfusion, during the patient's first admission with an $\mathrm{Hb}$ rate of $7.1 \mathrm{~g} / \mathrm{dl}$ (baseline: $6.9-8 \mathrm{~g} /$ $\mathrm{dl}$ ), was based on insufficient evidence. A referral institution or the hematology consultant should have been contacted and asked to provide transfusion advice. Second, the patient's DHTR was misdiagnosed in the Emergency Room when he was readmitted into the Sens Medical Center, even though the patient was exhibiting all of the clinical and biological signs of DHTR. Furthermore, we also noticed that neither the patient's reticulocyte count or $\mathrm{HbA}$ and $\mathrm{HbS}$ percentages were measured between his first admission and the onset of DHTR/HS on day 12, when the decision was made to refer the patient to the Henri-Mender University Hospital in Creteil. Indeed, this clinical case clearly illustrates the need to provide clinicians with streamlined information and guidelines for managing patients with SCD [16,17] especially guidelines pertaining to blood transfusion. Such recommendations must be strictly respected if we are to manage or prevent DHTR in patients with sickle cell disease. Clinicians should take these recommendations into consideration in order to optimize transfusion practice and avoid the risk of DHTR in less well-known and less-well monitored patients and in patients who do not undergo transfusions on a regular basis. Habibi et al. [3] reported that DHTR occurs in patients who receive relatively few transfusions (10 RBC units on average), and that, for more than half of these patients, the transfusion that triggered the episode was prescribed as a one-off preventive measure; these patients had rarely, if ever, been transfused. Whenever patients with SCD are admitted into the hospital, an investigation should be carefully carried out to learn about the individual's transfusion history and any episode involving prior antibodies. Thus, close communication between clinicians and the blood transfusion center is crucial. If a transfusion is necessary, national recommendations concerning patients with SCD must be followed. The use of $\mathrm{Rh}$-Kell matched $\mathrm{RBC}$ units has reduced alloimmunization and hemolytic transfusion reactions [18]. The incidence of alloimmunization to RBC antigens in transfused patients with SCD is approximately $20-25 \%$, which is greater than that of the general population [2,19]. Following alloimmunization, a rapid reduction in alloantibody titer may make the antibody undetectable by routine screening, hence the need for accurate records. A centralized database, accessible across health-care systems, that includes patient red cell antibody histories should be created to inform the transfusing facility of previously identified antibodies (even if they are no longer detectable) and thereby ensure the selection of compatible RBC units for transfusion.

Although no standard treatment exists, managing patients with DHTR necessitates the avoidance of further transfusions because they can cause hemolysis to worsen. However, if the patient presents with rapid hemolysis and severe anemia, then a transfusion may be necessary. In such cases, intravenous immunoglobulin (IVIG) and Erythropoietin (EPO) should be administered concurrently [7]. For severe cases, EPO-Eculizumab should be considered [3-20]. In cases where additional transfusions are necessary, EPO-Rituximab may prove successful [3].

\section{Conclusion}

DHTR is a serious and potentially life-threatening complication of RBC transfusion. All clinicians managing patients with SCD must be aware of the risk of DHTR to ensure prompt recognition and management. Indications for transfusion according to national recommendations should be followed. To minimize adverse events or transfusion-related reactions, close liaison with the blood bank is necessary. Such cooperation will provide the help needed to investigate any current or historical antibodies in less well-known and less-well monitored patients who may be at high risk for developing DHTR. DHTR should be appropriately investigated and reported to the National Haemovigilance Network. 
Citation: Nsimba B, Habibi A, Pirenne F, Bartolucci P, Tonduangu D, et al. (2017) Fatal Delayed Hemolytic Transfusion Reaction and Hyperhemolysis without Detectable Alloantibodies or Autoantibodies in a Patient with Sickle Cell Disease: A Case Report and Literature Review. J Blood Disord Transfus 8: 388. doi:10.4172/2155-9864.1000388

Page 5 of 5

\section{Acknowledgments}

The authors would like to thank Mrs. Gael Nsimba of the Paris-Sud University, School of Medicine, for her contribution in collecting data from the literature.

\section{References}

1. Gomes E, Castetbon K, Goulet V (2015) Sickle cell deaths in France: Age of death and associated causes (1979-2010). BEH 8: 142-150.

2. Howard J, Telfer P (2015) Sickle cell disease in clinical practice. SpringerVerlag Edition, London.

3. Habibi A, Mekontso-Dessap A, Guillaud C, Michel M, Razazi K, et al (2016) Delayed hemolytic transfusion reaction in adult sickle-cell disease: Presentations, outcomes, and treatments of 99 referral center episodes. Am J Hematol 91: 989-994.

4. Amr El-Husseini, Sabry A (2002) Fatal hyperhemolytic delayed transfusion in sickle cell disease: A case report and literature review. Am Emerg Med 28: 5-8.

5. Win N, New H, Lee E, Fuente JDL (2008) Hyperhemolysis syndrome in sickle cell disease. Case report (recurrent episode) and literature review Expert Rev. Hematol 2: 111-115.

6. McGlennan AP, Grundy EM, (2005) Delayed haemolytic transfusion reaction and hyperhaemolysis complicating peri-operative blood transfusion in sickle cell disease. Anaesthesia 60: 609-612.

7. Dessap MA, Pirenne F, Razazi K, Moutereau S, Abid S, et al. (2016) A diagnosis nomogram for delayed hemolytic transfusion reaction in sickle cell disease. Am J Hematol 91: 1181-1184.

8. Delaney M, Wendel S, Bercovitz RS, Cid J, Cohn C, et al. (2016) Transfusion reactions: prevention, diagnosis, and treatment. The Lancet 388: 2825-2836.

9. Vidler JB, Gardner K, Amenyah K, Mijovic A, Thein SI (2015) Delayed haemolytic transfusion reaction in adults with sickle cell disease: A 5-year experience. Br J Haematol 169: 746-753.
10. Cox JV, Steane E, Cunningham G, Frenkel EP (1988) Risk of alloimunization and delayed hemolytic transfusion reactions in patients with sickle cell disease. Arch Inter Med 148: 2485-9.

11. Mendoza R, Moore M, Passwater M, Fadeyi EA (2011) Delayed hemolytic transfusion reaction without detectable autoantibodies or alloantibodies. A possible role of phosphatidylserine exposure on donor RBCs. Rounds 42: 653-656.

12. Francoz C, Durand F (2007) Artificial supplementation of the liver by the MARSTM system: Interest and limitations in resuscitation. Resuscitation 16: 587-594.

13. Noizat-Pirenne F, Habibi A, Mekontso-Dessap A, Razazi K, Chadebech P, et al. (2015) The use of rituximab to prevent severe delayed haemolytic transfusion reaction in immunized patients with sickle cell disease. Vox Sang.108: 262-267.

14. Castro O, Oneal P, Medina A, Onojobi G, Gordeuk VR (2016) Preventing delayed hemolytic transfusion reaction in sickle cell disease. Transfusion 56: 2899-2900.

15. Pinto PC, Braga JA, Santos DAM (2011) Risk factors for alloimmunization in patients with sickle cell anemia. Rev Assoc Med Bras 57: 654-659.

16. Lionnet F, Arlet JB, Bartolucci P, Habibi A, Ribeil JA, et al. (2009) Practical recommendations for the management of sickle cell anemia. S Afr Med J 30: 162-223.

17. Davis BA, Allard S, Qureshi A, Porter JB, Pancham S, et al. (2017) Guidelines on red cell transfusion in sickle cell disease. Part II: Indications for transfusion. Br J Haematol 176: 192-209.

18. Noizat-Pirenne F, Yazdanbakhsh K, Ware ER (2012) Impact of alloimmunization on post-transfusion haemolysis during sickle cell anemia. Transfus Med Hemother 19: 132-138.

19. Costa FF, Conra N (2016) Sickle cell anemia. Springer International Publishing Edition, Switzerland.

20. Dumas G, Habibi A, Onimus T, Merle J, Razazi K, et al. (2016) Eculizumab salvage therapy for delayed hemolysis transfusion reaction in sickle cell disease patients. Blood 127: 1062-1064. 